\title{
New strategy of synthesis, characterization, theoretical study and inhibition effect on mild steel corrosion in acidic solution
}

\author{
Nadia Arrousse ${ }^{1}$, El Houssine Mabrouk ${ }^{1,2}$, Belkheir Hammouti ${ }^{3}$, Fadoua El hajjaji ${ }^{1, *}$, Zakia Rais ${ }^{1}$ and \\ Mustapha Taleb ${ }^{1}$ \\ ${ }^{1}$ Laboratory of Engineering, organometallic, Molecular and Environment (LIMMOME), Faculty of Sciences, \\ University Sidi Mohamed Ben Abdellah, Fez, Morocco \\ ${ }^{2}$ Laboratory of Materials Engineering for the Environment \& Natural Resources, Department of Chemistry, \\ Faculty of Sciences and Technics, BP 509 Boutalamine, Errachidia, Moulay Ismail University Meknes, Morocco \\ ${ }^{3}$ LCAE, Faculty of Sciences, Med first University, Oujda
}

\begin{abstract}
We report two new different synthesis strategies of an eco-friendly organic dye 3-oxo-3Hspiro[isobenzofuran-1,9'-xanthene]-3',6'-diyl diacetate. These methods were based on the reaction of fluorescein with acetic anhydride under different experimental conditions. The synthesized heterocyclic system obtained with excellent yield was characterized by FT-IR, ${ }^{1}$ H N.M.R., ${ }^{13}$ C N.M.R., and mass spectrometry. This reaction has also been studied theoretically using Gaussian 09 based on the DFT method at B3LYP/6-31G (d, p). The results obtained are in good correlation with those obtained experimentally. The inhibition behavior of the synthetic product has been studied using absorbance difference measurement, the percentage of inhibition efficiency attains $90 \%$ at $10^{-4} \mathrm{M}$ of NAR3 inhibitor. The surface analysis of mild steel was investigated using scanning electron microscopy (S.E.M.) and Energy Dispersive X-ray (E.D.X.) methods and show the adsorption behavior of inhibitor on the surface of mild steel.
\end{abstract}

Keywords: $O$-alkylation; heterocyclic compounds; DFT; B3LYP/6-31G base (d, p); X-ray (E.D.X.); scanning electron microscopy (S.E.M.).

\section{Introduction}

Considerable attention has directed toward finding heterocyclic organic compounds previously used in synthetic organic chemistry in many chemical areas. Heterocyclic systems have recently attracted much attention because they have various abilities such as anti-microbial, anti-tumor, anti-epileptic, antihistaminic, anti-oxidant and anti-inflammatory actions ${ }^{1-17}$; and they are being used as lead compounds for drug development ${ }^{18}$. As the results of several recent studies have indicated that some heterocyclic compounds derivatives synthesized have a diversity of useful biological effects including antibacterial, antifungal, analgesic, antiviral, anticancer, antihypertensive, anticonvulsant, and anti-diabetic properties ${ }^{19-25}$. They are also widely utilized as a building block in numerous materials and compounds ${ }^{26}$. In recent years, they have been employed in numerous high-tech applications including molecular motors ${ }^{27}$, machines ${ }^{28,29}$ and switches ${ }^{30,31}$. Our team has been investigating the fluorescein for their biological activity for several years-for example, anticancer, antibacterial and antifungal $^{32,33}$. The synthesis of heterocyclic esters

*Corresponding author: Fadoua El hajjaji

Email address: el.hajjajifadoua25@gmail.com

DOI: http://dx.doi.org/10.13171/mjc10502005151417feh is an interesting issue because these compounds are very useful substrates and important intermediates for the construction of various natural or bioactive molecules. The development of efficient methods for the formation of the $\mathrm{C}-\mathrm{O}$ bond via the acylation of $\mathrm{O}-\mathrm{H}$ bonds is one of the important and perpetual subjects in organic synthetic chemistry. Following the research done on the synthesis of heterocyclic systems, we focused on this work on the new strategy of synthesis of 3-oxo-3H-spiro[isobenzofuran-1,9'-xanthene]-3',6'-diyl diacetate to have access to new active biomolecule with an excellent yield. The same product was synthesized by Hossein Eshghi ${ }^{34}$, catalytically using $\mathrm{P}_{2} \mathrm{O}_{5} / \mathrm{SiO}_{2}$ according to the reaction between fluorescein and acetic acid. Our way of synthesizing this product is very important because it is more economical and is a more environmentally friendly alternative than the catalytic process. Our two approaches also achieve better efficiency. Then, the synthetic compound has several aromatic rings that can be used as an inhibitor against corrosion. For that, the anticorrosion activity of synthetic product has been evaluated using the difference absorbance method and the surface of mild steel analysis using

Published May 15, 2020 
SEM/EDX technical. The theoretical study represents a global analysis that gives information on several parameters, among them; we find the energy value of the free enthalpy of the reaction that demonstrates us, not only the spontaneity of the reaction but also its exact energy value ${ }^{35,36}$.

\section{Results and discussions of the synthesis reaction}

The $O$-alkylation reaction is one of the methods for the preparation of esters by creating new oxygencarbon bonds. In the first method, this is a particularly efficient synthesis of the 3-oxo-3H-spiro diacetate [isobenzofuran-1,9'-xanthene] -3',6'-diyl in high yield by direct reaction between fluorescein 1 and acetic anhydride $\mathbf{2}$ (Scheme 1).

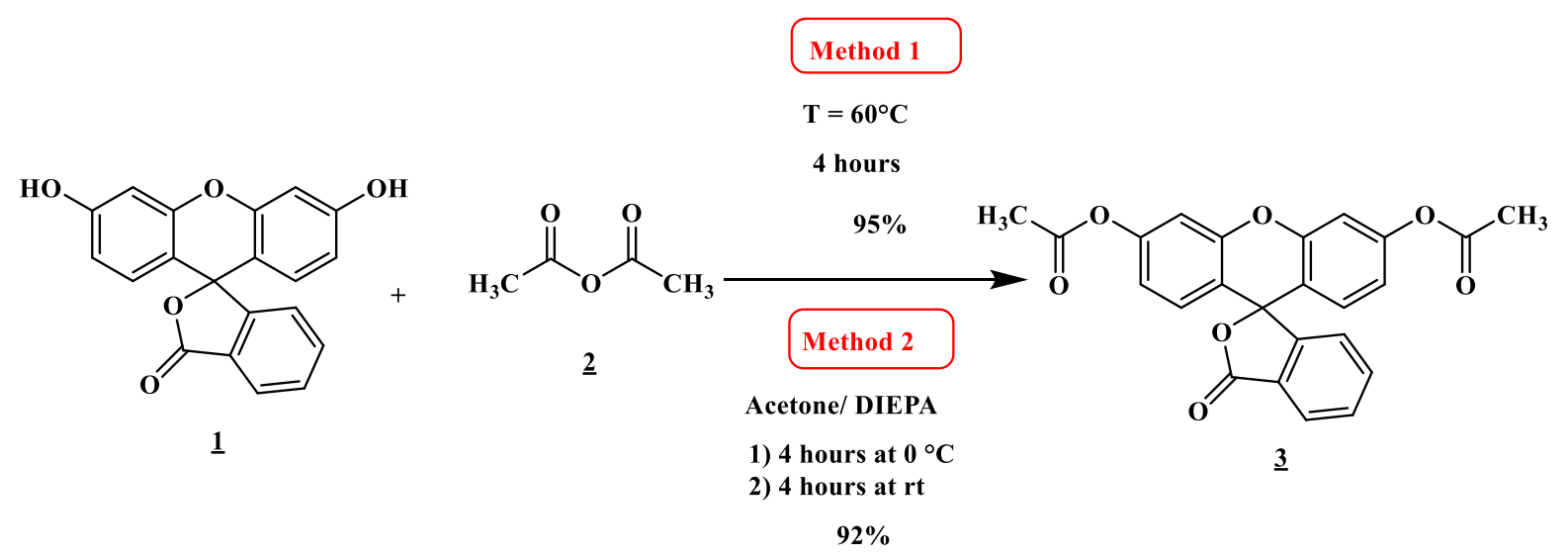

Scheme 1. $O$-alkylation reaction of acetic anhydride $\mathbf{2}$ with fluorescein $\mathbf{1}$.

The product: 3-oxo-3H-spiro[isobenzofuran-1,9'xanthene]-3',6'-diyl diacetate 3 was obtained with an excellent chemical yield by $O$-alkylation of acetic anhydride 2 with fluorescein 1 for 4 hours at $60^{\circ} \mathrm{C}$. It was determined by nuclear magnetic resonance, infrared and mass spectrometry.

The second method used for the synthesis of this product which consists of working in a basic medium aims to compare the reaction time and the yield of the two methods. Indeed, the reaction of acetic anhydride $\mathbf{2}$ with fluorescein $\mathbf{1}$ was carried out in dry acetone for 4 hours at $0^{\circ} \mathrm{C}$ in addition to 4 hours at room temperature in the presence of diisopropylethylamine.

From the results obtained experimentally, it can be seen that although the yields are comparable, the short duration of the reaction and the absence of the solvent and the base give the advantage and favor the use of the first method over to the second.

On the other hand, we expect initially to obtain several products with different yields. Still, the theoretical study reported in this work clearly shows the spatial symmetry of the fluorescein molecule, which justifies the formation of a single product. The interpretation of the spectra clearly shows the compatibility between the two experimental and theoretical studies. Indeed, the two carbons of the two methyl groups $\left(\mathbf{C H}_{3}\right)$ of compound $\mathbf{3}$ occupy the same environment, the same is observed for the three protons of each methyl group which appear in the form of a singular attributed to the six protons.

\section{3-oxo-3H-spiro[isobenzofuran-1,9'-xanthene]- 3',6'-diyl diacetate 3 :}

Yield $=95 \% ;$ Melting point (acetone/ethanol): 200-202 ${ }^{\circ} \mathrm{C} ; \mathrm{R}_{\mathrm{f}}=0.80$ (Ether/Hexane, 80: 20).

${ }^{1} \mathrm{H}-\mathrm{NMR}$ (Bruker, 300.13 MHz, CDCl 3$): \delta(\mathrm{ppm})=$ $2.34\left(\mathrm{~s}, 6 \mathrm{H}, 2 \mathrm{CH}_{3}\right), 6.80-6.88\left(\mathrm{~m}, 4 \mathrm{H}, \mathrm{H}_{\text {arom }}\right)$, 7.10-7.24 (m, 3H, $\mathrm{H}_{\text {arom }}$ ), 7.60-8.10 (m, 3H, $\left.\mathrm{H}_{\text {arom }}\right)$.

${ }^{13}$ C-NMR (75.47 MHz, $\left.\mathbf{C D C l}_{3}\right): \delta(\mathrm{ppm})=21.12$ $\left(2 \mathrm{CH}_{3}\right), 88.6\left(1 \mathrm{C}_{\mathrm{cyc}} \mathrm{O}-\right), 110.05(2 \mathrm{C}), 116.48(1 \mathrm{C})$, 117.8 (2C), 124.1 (1C), 125.26 (1C), 126.16 (1C), 129.01 (2C), 130.11 (1C), 135.32 (1C), 151.59 (2C), $152.06(3 \mathrm{C}), 152.90(1 \mathrm{C})\left(\mathrm{C}_{6} \mathrm{H}_{5}\right.$ aromatic carbons), $168.84(3 \mathrm{C}=\mathrm{O})$.

MS-EI: $416.4[\mathrm{M}], \mathrm{C}_{24} \mathrm{H}_{16} \mathrm{O}_{7}$.

FT-IR (KBr) $\tilde{\mathbf{V}}\left(\mathbf{c m}^{-1}\right) 3035 v(=\mathrm{C}-\mathrm{H}$, arom), $1760 v$ $(\mathrm{C}=\mathrm{O}$, lactone $), 1596 \vee(\mathrm{C}=\mathrm{C}$, arom. $), 1485,1427$, $1371 v(\mathrm{C}-\mathrm{O})$.

\subsection{General}

Melting points were determined with an Electrothermal melting point apparatus and are uncorrected. N.M.R. spectra $\left({ }^{1} \mathrm{H},{ }^{13} \mathrm{C}\right)$ were recorded on a Bruker AM 300 (operating at $300.13 \mathrm{MHz}$ for ${ }^{1} \mathrm{H}$, at $75.47 \mathrm{MHz}$ for ${ }^{13} \mathrm{C}$ ) spectrometer (Regional University Center of Interface, $\mathrm{Fez}$ ) in $\mathrm{CDCl}_{3}$ solution. N.M.R. data are listed in $\mathrm{ppm}$ and are reported relative to tetramethylsilane $\left({ }^{1} \mathrm{H},{ }^{13} \mathrm{C}\right)$; residual solvent peaks being used as an internal standard. T.L.C followed all reactions. T.L.C. analyses were carried out on $0.25 \mathrm{~mm}$ thick precoated silica gel plates (Merck Fertigplatten Kieselgel 60F254) and spots were visualized under U.V. light or by exposure to vaporized iodine. FT-IR spectra were recorded on an Avatar 370 FT-IR spectrometer in the form of $\mathrm{KBr}$ pellets. Mass 
spectra were recorded on a Polaris Q Ion Trap G.C./MSn Mass Spectrometer (Regional University Center of Interface, Fez). References $\mathbf{1}$ and $\mathbf{2}$ were used successively for fluorescein and acetic anhydride in the synthesis section. The references used in the theoretical study are R1 and R2. NAR3 is the reference for the synthetic product used in the part of Anticorrosive behavior.

\subsection{Absorbance method}

The material used in this work is mild steel with the following chemical composition: $\mathrm{Fe}$ (99.21), C (0.21), Mn (0.05), Si (0.38), S (0.05), P (0.09) and Al (0.01). The mild steel surface was polished with emery paper (until 1500). Washed with distilled water, decreasing by acetone and dry before the start of each experiment used in this study. The molar hydrochloric acid (1M) was prepared by dilution of analytical grade $37 \%$. The concentration range of the studied inhibitor was $10-{ }^{4} \mathrm{M}-10^{-7} \mathrm{M}$.). The mild steel samples are immersed in these solutions and placed in thermostated water during $6 \mathrm{~h}$ at $298 \mathrm{~K}$. Then, the absorbance measurements $\left(\mathrm{A}^{\circ}\right)$ and $(\mathrm{A})$ are taken before and after immersion at a wavelength of 300310nm using U.V./Visible spectrophotometer (UV-6300PC, Double Beam Spectrophotometer).

\subsection{Surface analysis}

The scanning electron microscopy (S.E.M.) is an excellent method for surface morphology analysis. This technique can confirm the higher protective behavior of the studied inhibitors. The S.E.M. technique performed after an immersion during 6hours in the presence and absence of NAR3 inhibitor at an optimum concentration of $10^{-4} \mathrm{M}$. The materiel composition is obtained using E.D.X. attached to the scanning electron microscopy with an acceleration voltage of $20 \mathrm{kV}$.

\subsection{A typical procedure for $\mathrm{O}$-alkylation Method 1}

$0.5 \mathrm{~g}$ of fluorescein dissolved in acetic anhydride was heated to a temperature of $60^{\circ} \mathrm{C}$. After 4 hours, T.L.C. on silica gel (Ether/Hexane, 80:20) showed complete conversion of the starting material and the presence of a new product. The product was purified by recrystallization from a mixture of acetone and ethanol. The product was obtained in the form of a crystalline solid with a yield of $95 \%$.

\section{Method 2}

To a stirring solution of fluorescein $(0.34 \mathrm{~g}, 1 \mathrm{mmol})$ in $5 \mathrm{~mL}$ of solvent cooled to $0^{\circ} \mathrm{C}$ was added $1.1 \mathrm{mmol}$ of the base. Acetic anhydride $(0.4 \mathrm{~g}$, $4 \mathrm{mmol}, 4.0$ equiv) in $3 \mathrm{~mL}$ of solvent was added dropwise over $2 \mathrm{~h}$ with continuous cooling. The solution was cooled an additional $2 \mathrm{~h}$. After 4 hours. The conversion of the starting material was complete, and a new product was noticed. The solvent was evaporated under reduced pressure. The residue was quenched with a saturated aqueous solution of ammonium chloride $(20 \mathrm{~mL})$ and extracted with dichloromethane $(20 \mathrm{~mL} \times 3)$. The organic phase was dried in sodium sulfate $\left(\mathrm{Na}_{2} \mathrm{SO}_{4}\right)$, and the solvent was removed under reduced pressure. The product was purified by twice recrystallization from acetone/ methanol. The product was obtained as a white solid with a good yield of $92 \%$.

\section{Theoretical study of the synthesis reaction}

\subsection{Optimization of interatomic distances and determination of the density of charges and the angles of the reagents}

The optimized structures allow direct access to all the parameters related to the geometry of the molecules, namely: the densities of charges, the interatomic distances, the angles ... All our calculations were performed by the DFT/ B3LYP density functional theory method, with the base 6-31G (d, p). Tables 1 and 2 give the values of these quantities. Figures 1 and 2 respectively represent the geometries of optimized reagents.

The C3 atom of R1 has the highest charge density value of all atoms, while the $\mathrm{C} 2$ and $\mathrm{C} 4$ atoms of $\mathrm{R} 2$ has a charge density value of +0.580 higher than that of the other atoms of acetic anhydride.

Table 1. The density of charge of the atoms of the two reagents in (e).

\begin{tabular}{|c|c|c|c|}
\hline \multicolumn{2}{|c|}{ Fluorescein (R1) } & \multicolumn{2}{c|}{ acetic anhydride (R2) } \\
\hline $\mathbf{C}_{\mathbf{1}} ; \mathbf{C}_{\mathbf{7}}$ & 0.11 & $\mathbf{C}_{\mathbf{1}} ; \mathbf{C}_{\mathbf{5}}$ & -0.386 \\
\hline $\mathbf{C}_{\mathbf{2}} ; \mathbf{C}_{\mathbf{8}}$ & 0.28 & $\mathbf{C}_{\mathbf{2}} ; \mathbf{C}_{\mathbf{4}}$ & 0.587 \\
\hline $\mathbf{C}_{\mathbf{3}} ; \mathbf{C}_{\mathbf{1 1}} ; \mathbf{C}_{\mathbf{1 3}}$ & -0.14 & $\mathbf{O}_{\mathbf{3}}$ & -0.482 \\
\hline $\mathbf{C}_{\mathbf{4}}$ & -0.19 & $\mathbf{O}_{\mathbf{6}} ; \mathbf{O}_{\mathbf{7}}$ & -0.403 \\
\hline $\mathbf{C}_{\mathbf{5}} ; \mathbf{C}_{\mathbf{1 9}}$ & -0.12 & & \\
\hline $\mathbf{C}_{\mathbf{6}} ; \mathbf{C}_{\mathbf{1 2}}$ & 0.33 & & \\
\hline $\mathbf{C}_{\mathbf{9}}$ & 0.06 & & \\
\hline $\mathbf{O}_{\mathbf{1 5}} ; \mathbf{O}_{\mathbf{1 6}}$ & -0.57 & & \\
\hline $\mathbf{O}_{\mathbf{1 8}}$ & -0.56 & \\
\hline $\mathbf{O}_{23}$ & -0.50 & \\
\hline $\mathbf{O}_{25}$ & -0.51 & \\
\hline
\end{tabular}


Table 2. Interatomic distances in $(\AA)$ and angles in $\left(^{\circ}\right)$ corresponding to reagents.

\begin{tabular}{|c|c|c|}
\hline Reagents & Distance $\AA$ & Angle $^{\circ}$ \\
\hline $\mathbf{R} 1$ & $\begin{array}{c}\mathrm{dC}_{1}-\mathrm{C}_{2}=1.396 \\
\mathrm{dC}_{1}-\mathrm{C}_{3}=1.405 \\
\mathrm{dC}_{3}-\mathrm{H}_{26}=1.085 \\
\mathrm{dC}_{3}=\mathrm{C}_{5}=1.384 \\
\mathrm{dC}_{5}-\mathrm{C}_{6}=1.404 \\
\mathrm{dC}_{6}-\mathrm{O}_{16}=1.362 \\
\mathrm{dO}_{16}-\mathrm{H}_{33}=0.966 \\
\mathrm{dC}_{2}-\mathrm{O}_{10}=1.369 \\
\mathrm{dC}_{24}=\mathrm{O}_{25}=1.206 \\
\mathrm{dC}_{18}-\mathrm{C}_{24}=1.482 \\
\mathrm{dC}_{9}-\mathrm{C}_{17}=1.523\end{array}$ & $\begin{array}{l}\mathrm{A}\left(\mathrm{C}_{1}, \mathrm{C}_{2}, \mathrm{O}_{3}\right)=109.613^{\circ} \\
\mathrm{A}\left(\mathrm{O}_{3}, \mathrm{C}_{2}, \mathrm{O}_{6}\right)=123.674^{\circ} \\
\mathrm{A}\left(\mathrm{C}_{2}, \mathrm{O}_{3}, \mathrm{C}_{4}\right)=121.072^{\circ}\end{array}$ \\
\hline $\mathbf{R 2}$ & $\begin{aligned} \mathrm{dC}_{1}-\mathrm{H}_{9} & =1.091 \\
\mathrm{dC}_{1}-\mathrm{C}_{2} & =1.505 \\
\mathrm{dC}_{2}-\mathrm{O}_{3} & =1.395 \\
\mathrm{dC}_{2}=\mathrm{O}_{6} & =1.198\end{aligned}$ & $\begin{array}{c}\mathrm{A}\left(\mathrm{C}_{1}, \mathrm{C}_{2}, \mathrm{O}_{3}\right)=109.9131^{\circ} \\
\mathrm{A}\left(\mathrm{O}_{3}, \mathrm{C}_{2}, \mathrm{O}_{6}\right)=123.476^{\circ}\end{array}$ \\
\hline
\end{tabular}

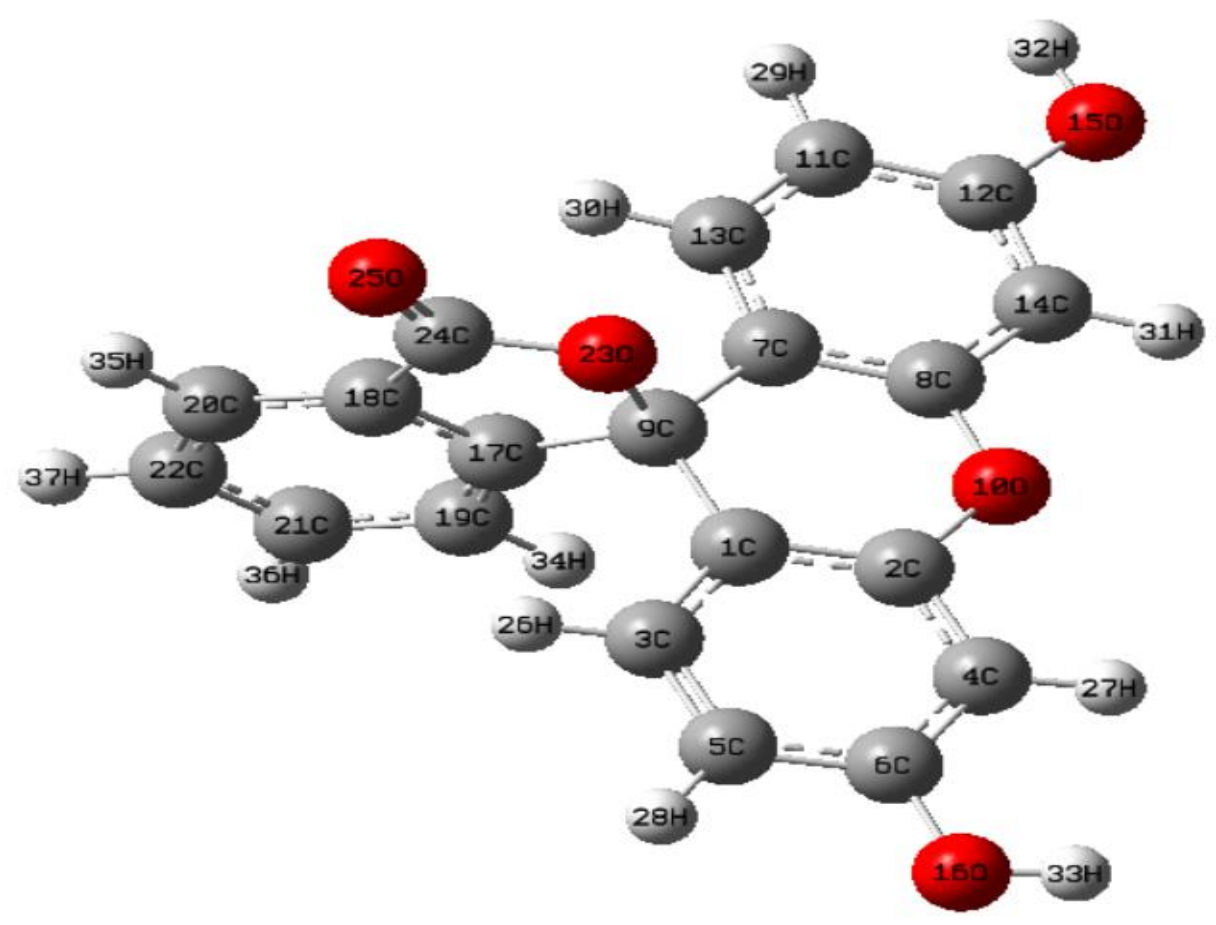

Figure 1. Fluorescein structure optimized by the method B3LYP / 6-31G (d, p)

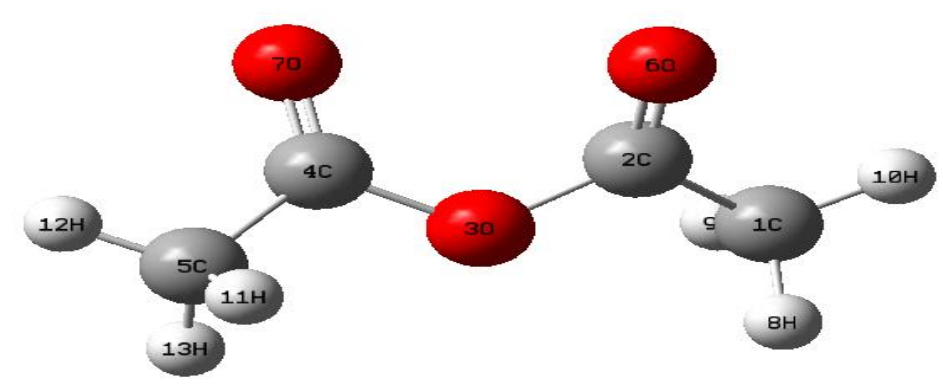

Figure 2. Structure of acetic anhydride optimized by the method B3LYP/6-31G (d, p)

4.2. Theoretical study of the condensation reaction of fluorescein $(\mathrm{R} 1)$ and acetic anhydride (R2)

\subsubsection{Thermodynamic study}

We have gathered some thermodynamic quantities characterizing the reaction between $\mathrm{R} 1$ on $\mathrm{R} 2$ in Table 3. 
Table 3. Thermodynamic quantities characterizing the reaction of fluorescein R1 and acetic anhydride R2 calculated using the method B3LYP/ 6-31G $(\mathrm{d}, \mathrm{p})$.

Thermodynamic quantities of the reaction

\begin{tabular}{|c|c|}
\hline$\Delta$ H (Kcal/mole $)$ & 18.6566 \\
\hline$\Delta \mathbf{S}($ Kcal $/$ mole.K) & -0.1850 \\
\hline$\Delta \mathbf{G}($ Kcal $/$ mole $)$ & -33.7824 \\
\hline
\end{tabular}

The enthalpy value of the $\Delta \mathbf{H}_{\mathbf{r}}$ reaction is positive, hence the endothermic nature of this reaction.

The free enthalpy variation $\Delta \mathbf{G}_{\mathbf{r}}$ that corresponds to the condensation reaction is negative; therefore, this reaction is thermodynamically favored.

\subsubsection{Prediction of electrophile / nucleophilic character of reagents}

To highlight the electrophilic/nucleophilic nature of the reagents, we calculated the reactivity parameters as follows:

- The HOMO / LUMO energy gaps of the reaction and the HOMO and LUMO molecular orbital energies of each reagent.

- The gap energies $\boldsymbol{\Delta} \mathbf{E}$, the electronic chemical potentials $\boldsymbol{\mu}$, the chemical hardness $\boldsymbol{\eta}$, the chemical softness $\mathbf{S}(\mathbf{I})$, the global electrophilic indices $\boldsymbol{\omega}$, the global nucleophilic indices $\mathbf{N}$ by the following equations ${ }^{31}$ :

$$
\begin{aligned}
& \Delta E(I)=E_{\text {номо }}(\text { fluo })-E_{\text {LUMo }}(\text { anhydride }) \quad E q .1 \\
& \Delta E(I I)=E_{\text {номо }}(\text { anhydride })-E_{L U M o}(\text { fluo }) \quad E q .2 \\
& \boldsymbol{\mu}=\left(\boldsymbol{E}_{\text {номо }}+\boldsymbol{E}_{L U м о}\right) / 2 \quad \boldsymbol{E q . 3} \\
& \boldsymbol{\eta}=\boldsymbol{E}_{\text {LUмо }}-\boldsymbol{E}_{\text {Hомо }} \quad \mathrm{Eq} .4 \\
& \omega=\mu^{2} / 2 * \eta \quad E q .5 \\
& \text { N=Eномо }-E_{\text {номо }}(\text { T.C.E. }) \quad \text { Eq.6 } \\
& \begin{array}{ll}
S(I)=1 / \eta & E q .7
\end{array}
\end{aligned}
$$

\begin{tabular}{|c|c|c|c|c|c|}
\hline Compound & $\mathbf{E}(\mathbf{e V})$ & HOMO (eV) & LUMO (eV) & $\Delta \mathbf{E}(\mathbf{I})(\mathbf{e V})$ & $\Delta \mathbf{E}(\mathbf{I I})(\mathbf{e V})$ \\
\hline Fluorescein & -31170.8014 & -6.0355 & -1.2887 & \multirow[b]{2}{*}{-5.2953} & \multirow[b]{2}{*}{-6.1658} \\
\hline Acetic anhydride & -10387.5536 & -7.4545 & -0.7401 & & \\
\hline
\end{tabular}

With TCE: Tetracyanoethylene,

Еномо $(\mathrm{TCE})=\mathbf{- 9 . 3 6 8 6 e V}$ calculated by DFT / B3LYP 6-31G (d, p).

Table 4. HOMO and LUMO energies and the energy differences between the two possible HOMO / LUMO combinations of the reagents by the functional B3LYP in combination the base $(6-31 \mathrm{G})(\mathrm{d}, \mathrm{p})$.

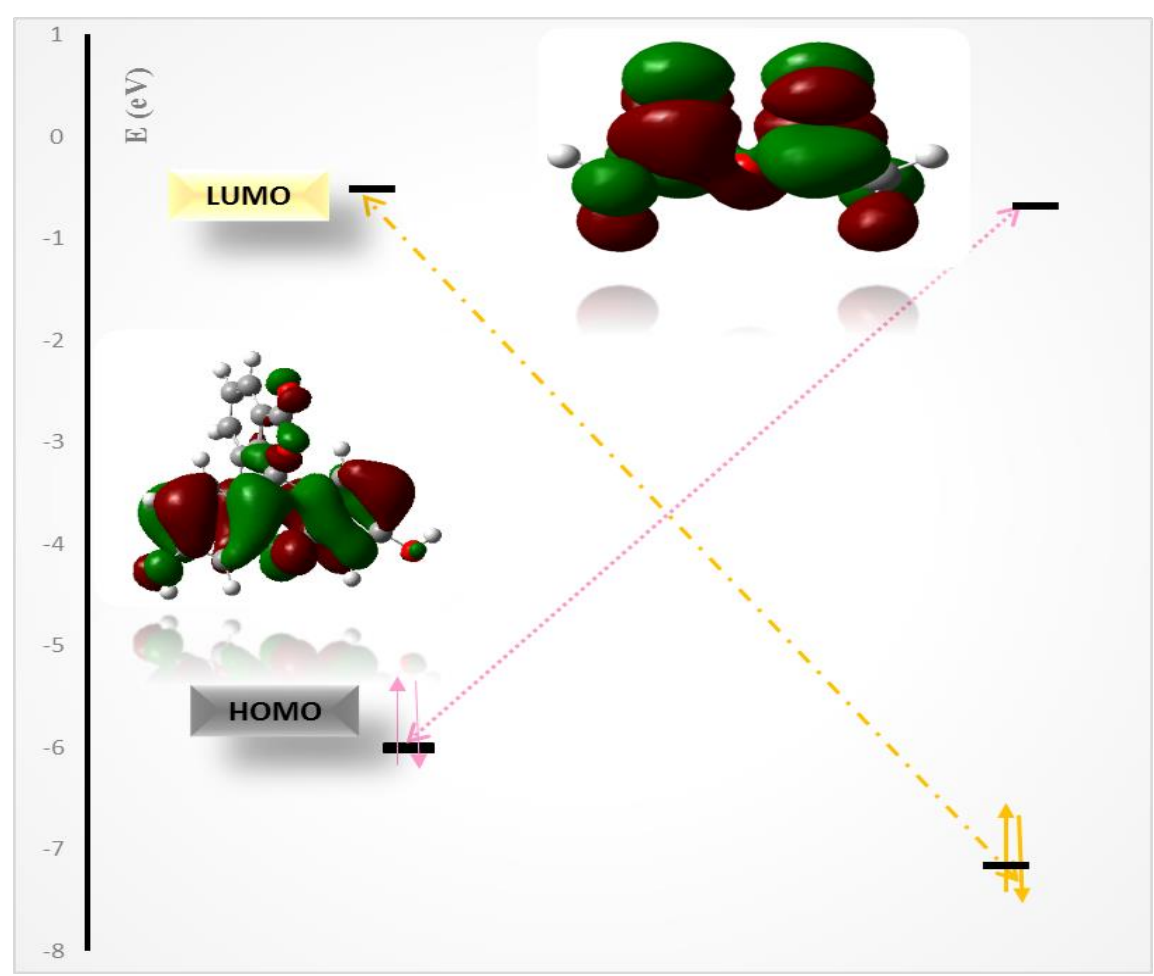

Figure 3. HOMO and LUMO Energy Diagram of Reagents 
The results from Table 4 and Figure 3 show that the gaps $\mid \boldsymbol{E}_{\text {номо }}(\mathrm{R} 1)-\boldsymbol{E}_{\text {LUмо }}$ (R2) | of the order of $\mathbf{5 . 2 9 5 3} \mathrm{eV}$ are energetically weaker than the gaps | $\boldsymbol{E}_{\text {номо }}(\mathrm{R} 2)$ - $\boldsymbol{E}_{\text {LUMo }}(\mathrm{R} 1) \mid$ which are of the order of 6.1658 eV. This allows us to conclude that the acetic anhydride (R2) has an electrophilic character while the fluorescein (R1) behaves like a nucleophile.

\subsubsection{Theoretical analysis of reagents by global properties}

Table 5 shows that the electronic chemical potential $\boldsymbol{\mu}$ of fluorescein $(\boldsymbol{\mu}=\mathbf{- 2 . 3 7 3 4} \mathbf{e V})$ is on a level of energy higher than that of acetic anhydride ( $\boldsymbol{\mu}=$ $3.3572 \mathrm{eV}$ ) which implies that electron transfer takes place from fluorescein to acetic anhydride. The global nucleophilicity $\mathbf{N}$ of fluorescein $(\mathbf{N}=\mathbf{3 . 0 8 3 0}$ eV) is significantly higher than that of acetic anhydride $(\mathbf{N}=\mathbf{1 . 6 6 4 0} \mathbf{e V})$ which means that fluorescein plays the role of a nucleophile whereas acetic anhydride is an electrophile. The same conclusion can be drawn from the values of the global electrophilicity $\boldsymbol{\omega}$. The chemical hardness of fluorescein $(\boldsymbol{\eta}=\mathbf{4 . 7 4 6 7} \mathbf{e V})$ is less than that of acetic anhydride $(\boldsymbol{\eta}=\mathbf{6 . 7 1 4 4} \mathbf{e V})$. This means that fluorescein retains few electrons in its environment. Then, the softness $\mathrm{S}(\mathrm{I})$ of the two reagents has close values, unlike acetic anhydride that maintains them in its environment. Consequently, the transfer of electrons takes place from fluorescein to acetic anhydride.

In conclusion, HOMO/LUMO Gap calculations, electronic chemical potentials, and global electrophilicity and nucleophilicity indices show the nucleophilic nature of fluorescein and the electrophilic character of acetic anhydride globally.

Table 5. Electronic chemical potential $\boldsymbol{\mu}$, chemical hardness $\boldsymbol{\eta}$, chemical softness $\mathbf{S}(\mathbf{I})$, global electrophilicity $\boldsymbol{\omega}$, global nucleophilicity $\mathbf{N}$, by the method B3LYP/6-31G (d, p).

\begin{tabular}{|c|c|c|c|c|c|c|}
\hline Compound & $\mathbf{E}(\mathbf{e V})$ & $\boldsymbol{\mu}(\mathbf{e V})$ & $\mathbf{\eta}(\mathbf{e V})$ & $\mathbf{S}(\mathbf{I})(\mathbf{e V})$ & $\boldsymbol{\omega}(\mathbf{e V})$ & $\mathbf{N}(\mathbf{e V})$ \\
\hline Fluorescein & -31170.8014 & -2.3734 & 4.7467 & 0.1053 & 0.5933 & 3.0830 \\
\hline Acetic anhydride & -10387.5536 & -3.3572 & 6.7144 & 0.0745 & 0.8393 & 1.6640 \\
\hline
\end{tabular}

Table 6. Natural populations of reagents calculated by the method B3LYP/6-31G(d, p).

\begin{tabular}{|c|c|c|c|c|c|}
\hline \multicolumn{6}{|c|}{ Natural populations } \\
\hline \multicolumn{3}{|c|}{ Fluorescein } & \multicolumn{3}{|c|}{ Acetic anhydride } \\
\hline Atoms & $\mathbf{P}(\mathbf{N})$ & $\mathbf{P}(\mathbf{N}-1)$ & Atoms & $\mathbf{P}(\mathbf{N})$ & $\mathbf{P}(\mathbf{N}+\mathbf{1})$ \\
\hline $\mathbf{C}_{1}$ & 6.15300 & 6.05094 & $\mathrm{C}_{1}$ & 6.78667 & 6.75448 \\
\hline $\mathbf{C}_{2}$ & 5.65370 & 5.61948 & $\mathbf{C}_{2}$ & 5.19341 & 5.38841 \\
\hline $\mathbf{C}_{3}$ & 6.18664 & 6.18842 & $\mathbf{O}_{3}$ & 8.57155 & 8.58342 \\
\hline $\mathrm{C}_{4}$ & 6.35306 & 6.32610 & $\mathrm{C}_{4}$ & 5.19341 & 5.38787 \\
\hline $\mathrm{C}_{5}$ & 6.30583 & 6.17120 & $\mathrm{C}_{5}$ & 6.78661 & 6.75449 \\
\hline $\mathrm{C}_{6}$ & 5.65439 & 5.63749 & $\mathbf{O}_{6}$ & 8.53138 & 8.68457 \\
\hline $\mathrm{C}_{7}$ & 6.15164 & 6.07941 & $\mathbf{O}_{7}$ & 8.53133 & 8.68419 \\
\hline $\mathrm{C} 8$ & 5.6562 & 5.63102 & & & \\
\hline $\mathrm{C}_{9}$ & 5.74195 & 5.75232 & & & \\
\hline $\mathrm{O}_{10}$ & 8.48562 & 8.36704 & & & \\
\hline $\mathrm{C}_{11}$ & 6.32575 & 6.21142 & & & \\
\hline $\mathrm{C}_{12}$ & 5.65537 & 5.64789 & & & \\
\hline $\mathrm{C}_{13}$ & 6.18392 & 6.17839 & & & \\
\hline $\mathrm{C}_{14}$ & 6.33306 & 6.29615 & & & \\
\hline $\mathrm{O}_{15}$ & 8.69874 & 8.67317 & & & \\
\hline $\mathrm{O}_{16}$ & 8.69839 & 8.66215 & & & \\
\hline $\mathrm{C}_{17}$ & 6.01968 & 6.03323 & & & \\
\hline $\mathrm{C}_{18}$ & 6.1753 & 6.1694 & & & \\
\hline $\mathrm{C}_{19}$ & 6.22323 & 6.21679 & & & \\
\hline $\mathbf{C}_{20}$ & 6.19041 & 6.18343 & & & \\
\hline $\mathbf{C}_{21}$ & 6.20644 & 6.19872 & & & \\
\hline $\mathrm{C}_{22}$ & 6.23717 & 6.22533 & & & \\
\hline $\mathbf{O}_{23}$ & 8.54861 & 8.53162 & & & \\
\hline $\mathrm{C}_{24}$ & 5.17982 & 5.17612 & & & \\
\hline $\mathbf{O}_{25}$ & 8.61000 & 8.58076 & & & \\
\hline
\end{tabular}


4.2.3. Prediction of local reactivity of reagents - Application of the Domingo polar model using Fukui indices $\mathbf{f k}^{+}$and $\mathbf{f k}^{-}$

According to Domingo's polar model ${ }^{37}$, the static indices of local electrophilicity $\omega_{\mathbf{k}}$ and local nucleophilicity $\mathbf{N}_{\mathbf{k}}$ are reliable descriptors for the prediction of the most favored electrophilicnucleophilic interaction for the formation of a chemical bond between two atoms. It occurs between the most electrophilic site (characterized by the highest value of $\omega_{\mathbf{k}}$ ) of the electrophilic molecule and the most nucleophilic site (characterized by the highest $\mathbf{N}_{\mathbf{k}}$ value) of the nucleophilic molecule. The local electrophilic values $\omega_{\mathbf{k}}$ for the reactive atoms, and the local nucleophilic $\mathbf{N}_{\mathbf{k}}$ of the acetic anhydride and fluorescein atoms calculated from the natural N.P.A. populations by the DFT/B3LYP 6-31G (d, p) method are reported in Table 6 and 7.

Table 7. Fukui indices ( $\mathbf{f} \mathbf{k}^{+}$and $\mathbf{f} \mathbf{k}^{-}$) and local electrophilicity values $\boldsymbol{\omega}_{\mathbf{k}}$ for reactive acetic anhydride atoms and $\mathbf{N}_{\mathbf{k}}$ local nucleophilicity for reactive fluorescein atoms calculated by N.P.A. natural population analysis.

Local indices N.P.A.

\begin{tabular}{|c|c|c|c|c|c|}
\hline \multicolumn{3}{|l|}{ Fluorescein } & \multicolumn{3}{|c|}{ Acetic anhydride } \\
\hline Atoms & $\mathbf{f}_{\mathrm{k}}^{-}$ & $\mathbf{N}_{\mathbf{k}}$ & Atoms & $\mathbf{f k}^{+}$ & $\mathbf{\Omega k}$ \\
\hline $\mathbf{C}_{1}$ & 0.102 & 0.305 & $\mathbf{C}_{1}$ & -0.032 & -0.027 \\
\hline $\mathbf{C}_{2}$ & 0.034 & 0.102 & $\mathbf{C}_{2}$ & 0.194 & 0.164 \\
\hline $\mathbf{C}_{3}$ & -0.002 & -0.005 & $\mathbf{O}_{3}$ & 0.012 & 0.010 \\
\hline $\mathrm{C}_{4}$ & 0.027 & 0.081 & $\mathrm{C}_{4}$ & 0.194 & 0.164 \\
\hline $\mathrm{C}_{5}$ & 0.135 & 0.402 & $\mathrm{C}_{5}$ & -0.032 & -0.027 \\
\hline $\mathrm{C}_{6}$ & 0.017 & 0.050 & $\mathrm{O}_{6}$ & 0.153 & 0.129 \\
\hline $\mathrm{C}_{7}$ & 0.072 & 0.216 & $\mathbf{O}_{7}$ & 0.153 & 0.128 \\
\hline $\mathrm{C}_{8}$ & 0.025 & 0.075 & & & \\
\hline $\mathrm{C}_{9}$ & -0.010 & -0.031 & & & \\
\hline $\mathbf{O}_{10}$ & 0.119 & 0.354 & & & \\
\hline$C_{11}$ & 0.114 & 0.342 & & & \\
\hline $\mathrm{C}_{12}$ & 0.007 & 0.022 & & & \\
\hline $\mathrm{C}_{13}$ & 0.006 & 0.017 & & & \\
\hline $\mathbf{C}_{14}$ & 0.037 & 0.110 & & & \\
\hline $\mathbf{O}_{15}$ & 0.026 & 0.076 & & & \\
\hline $\mathbf{O}_{16}$ & 0.036 & 0.108 & & & \\
\hline$C_{17}$ & -0.014 & -0.040 & & & \\
\hline $\mathrm{C}_{18}$ & 0.006 & 0.018 & & & \\
\hline $\mathrm{C}_{19}$ & 0.006 & 0.019 & & & \\
\hline $\mathbf{C}_{20}$ & 0.007 & 0.021 & & & \\
\hline $\mathbf{C}_{21}$ & 0.008 & 0.023 & & & \\
\hline $\mathrm{C}_{22}$ & 0.012 & 0.035 & & & \\
\hline $\mathrm{O}_{23}$ & 0.017 & 0.051 & & & \\
\hline $\mathrm{C}_{24}$ & 0.004 & 0.011 & & & \\
\hline $\mathbf{O}_{25}$ & 0.029 & 0.087 & & & \\
\hline
\end{tabular}

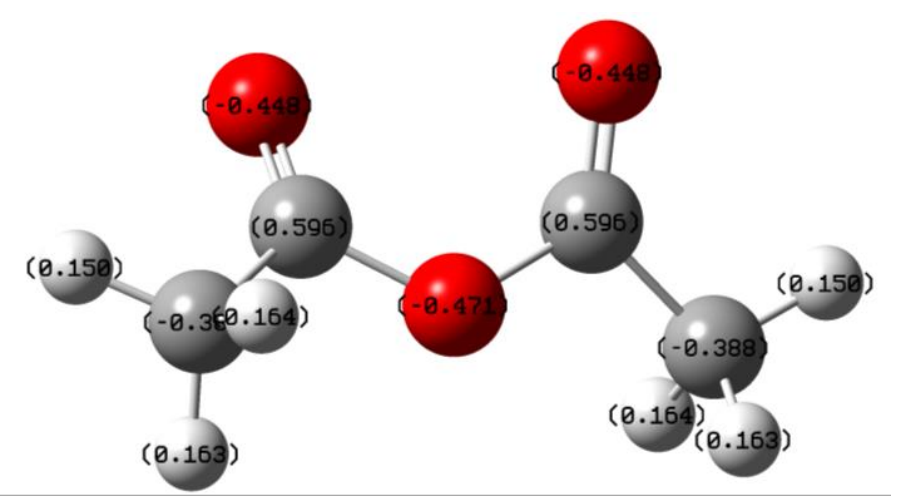

Figure 4. The charge density of the atoms of the acetic anhydride in (e). 
$\omega_{\mathrm{k}}=\omega^{*} \mathrm{fk}^{+} \quad$ Eq.8 $(\omega=0.8393 \mathrm{eV})$ and

$N_{k}=N^{-} \quad$ Eq.9 $(N=2.9881 e V)$

$\mathrm{fk}^{+}=\left[\mathbf{P}_{\mathbf{k}}(\mathrm{N}+1)-\mathbf{P}_{\mathrm{k}}(\mathrm{N})\right] \mathbf{E q . 1 0}$ for a nucleophilic attack

$f^{-}=\left[P_{k}(N)-P_{k}(N-1)\right]$ Eq.11 for an electrophilic attack

From where:

$\mathbf{P}_{\mathbf{k}}(\mathbf{N})$ : electron population of the atom $\mathrm{k}$ in the neutral molecule.

$\mathbf{P}_{\mathbf{k}}(\mathbf{N}+\mathbf{1})$ : electron population of the $\mathrm{k}$ atom in the anionic molecule.

$\mathbf{P}_{\mathbf{k}}(\mathbf{N}-1)$ : electron population of the $\mathrm{k}$ atom in the cationic molecule.
The results found are not in agreement with those desired in the synthesis. As the values of the Fukui indices are low in the $\mathbf{O}_{15}$ and $\mathbf{O}_{16}$ sites, this indicates that the neutral form of fluorescein does not give a good approach to the reaction. This requires not to work in a neutral environment. Indeed, it has been proposed to use two different conditions. The first procedure consists of direct condensation between fluorescein and acetic anhydride without the use of either solvent or base. The second involves the presence of acetone as solvent and pyridine as a base. In an acidic medium, fluorescein plays the role of a nucleophile through the free doublet located on the oxygen atoms of the two O.H. groups. In a basic medium, the base extracts the two hydrogens from the two O.H. groups of fluorescein. (Figure 5). $\mathbf{p H}$ remains moreover a parameter to be determined to lead to this reactive form of fluorescein.

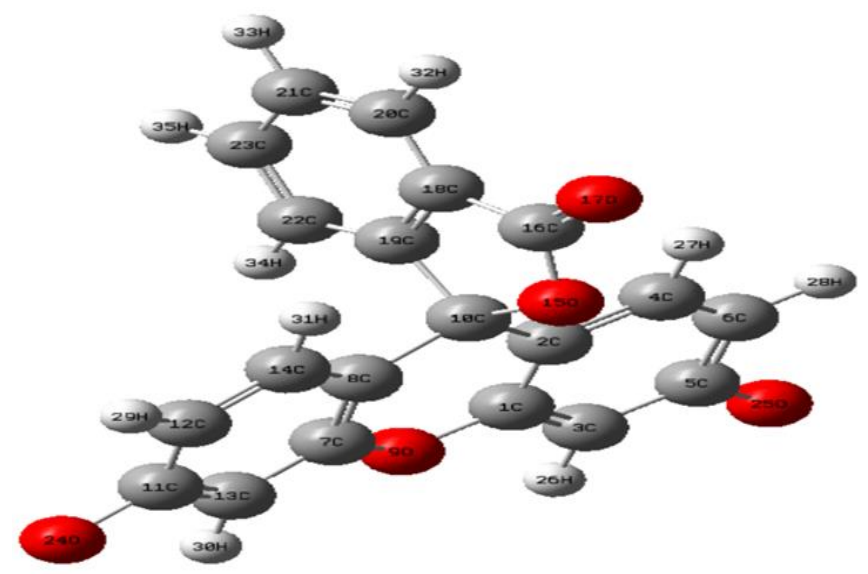

Figure 5. Structure of fluorescein in a basic medium optimized by the method B3LYP/6-31G(d, p)

The answer to this ambiguity was found by using the MARVINSKETCH software. The distribution of the protonated forms as a function of the $\mathbf{p H}$ shows that the desired shape can take place at a $\mathbf{p H}$ in the vicinity of 14 (Figure 6).
We proceeded by recalculating the same starting parameters, this time with fluorescein in basic medium.
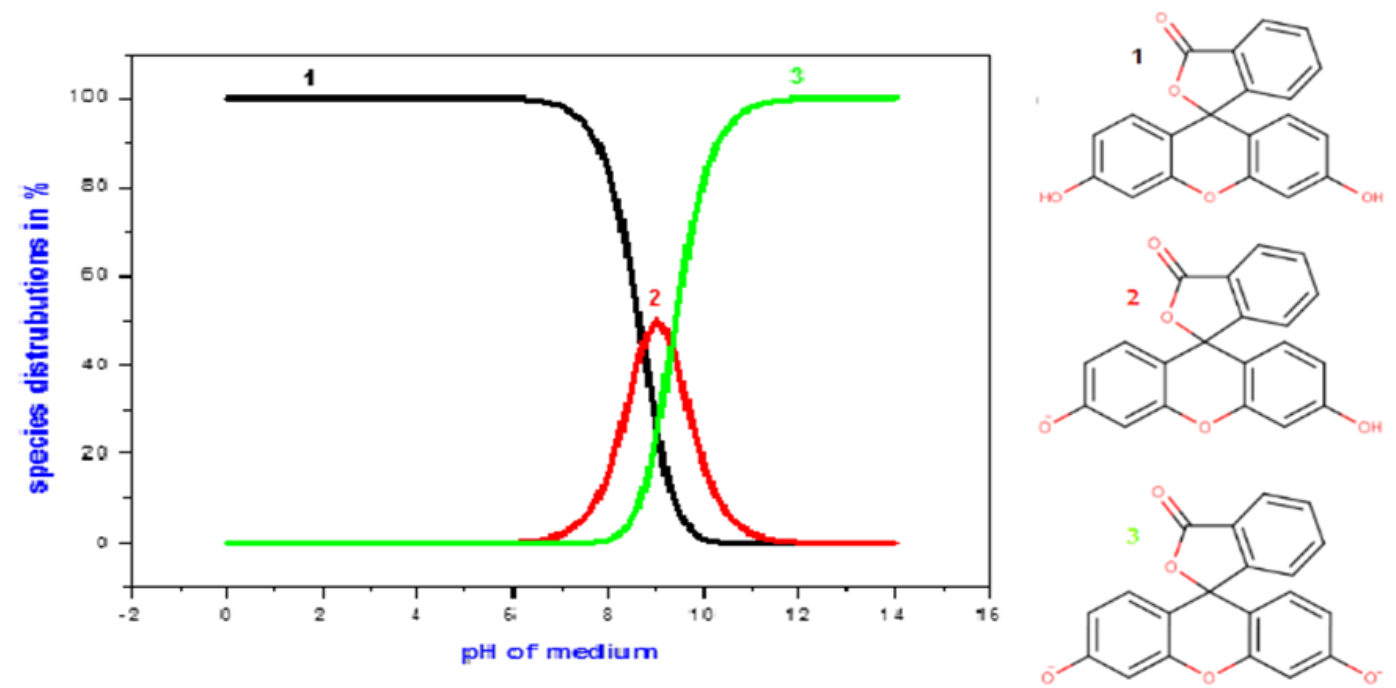

Figure 6. Distribution of different forms of fluorescein as a function of $\mathbf{p H}$ obtained from MARVISKETCH program 
Table 8. HOMO and LUMO energies and the energy differences between the two possible HOMO / LUMO combinations of reagents using the method B3LYP/6-31G (d, p).

\begin{tabular}{|c|c|c|c|c|c|}
\hline Compound & $\begin{array}{c}\mathbf{E} \\
(\mathbf{e V})\end{array}$ & HOMO (eV) & LUMO (eV) & $\Delta \mathbf{E}(\mathbf{I})(\mathbf{e V})$ & $\Delta \mathbf{E}(\mathbf{I I})(\mathbf{e V})$ \\
\hline Fluorescein (basic form) & -31144.6797 & -4.2678 & -1.2754 & & \\
\hline Acetic anhydride & -10387.5536 & -7.4545 & -0.7401 & -5.2953 & -6.1658 \\
\hline
\end{tabular}

The results from Table 8 show again that the $\mid \boldsymbol{E}_{\text {номо }}$ (fluo) - $\boldsymbol{E}_{\text {LUMo }}$ (acetic anhydride) | are energetically weaker than the $\mid \boldsymbol{E}_{\text {Hомо }}$ (acetic anhydride)- $\boldsymbol{E}_{\boldsymbol{L} \boldsymbol{U} \boldsymbol{M} \boldsymbol{O}}$ (fluo) | gaps and therefore acetic anhydride behaves as an electrophile while fluorescein behaves like a nucleophile.

\subsubsection{Theoretical analysis of reagents by global properties}

Table 9 shows that the chemical potential $\boldsymbol{\mu}$ of fluorescein $(\boldsymbol{\mu}=\mathbf{- 1 . 4 9 6 2 ~} \mathbf{e V})$ is on a level of energy higher than that of acetic anhydride $(\boldsymbol{\mu}=\mathbf{- 3 . 3 5 7 2} \mathbf{e V})$ which implies that electron transfer takes place from fluorescein to acetic anhydride. We note this time that the value of the nucleophilic index of basic fluorescein is higher than that found for the neutral fluorescein. This shows the importance of the use of the base in the desired reaction ensuring its right approach. On the other hand, the results obtained show that in basic medium, the nucleophilic index $(\mathrm{N}=4.8507 \mathrm{eV})$ higher than that of acetic anhydride $(\mathbf{N}=1.6640 \mathrm{eV})$ which means that fluorescein is a nucleophile whereas acetic anhydride is an electrophile. The same conclusion can be drawn from the values of electrophilic indices.

Figure 7 represents the distribution of the charge density on the atoms of the two reactants. The amount of electronic charge is located on the two oxygen atoms of the hydroxyl group O.H. of R1, on the other hand, the location of the amount of positive charge on the two atoms of the symmetrical carbon of the group $\mathrm{C}=\mathrm{O}$ of acetic anhydride $\mathrm{R} 2$. This confirms the results obtained.

Table 9. Electronic chemical potential $\boldsymbol{\mu}$, global hardness $\boldsymbol{\eta}$, global electrophilicity $\boldsymbol{\omega}$, global nucleophilicity $\mathbf{N}$, using the method B3LYP/6-31G (d, p).

\begin{tabular}{|c|c|c|c|c|c|c|}
\hline Compound & $\mathbf{E}(\mathbf{e V})$ & $\boldsymbol{\mu}(\mathbf{e V})$ & $\boldsymbol{\eta}(\mathbf{e V})$ & $\mathbf{S}(\mathbf{I})(\mathbf{e V})$ & $\boldsymbol{\omega}(\mathbf{e V})$ & $\mathbf{N}(\mathbf{e V})$ \\
\hline Neutral Fluorescein & -31171.2957 & -2.3468 & 4.6937 & 0.1065 & 0.5867 & 2.9881 \\
\hline Basic fluorescein & -31144.6797 & -1.4962 & 2.9924 & 0.1671 & 0.3741 & 4.8507 \\
\hline Acetic anhydride & -10387.5536 & -3.3572 & 6.7144 & 0.0745 & 0.8393 & 1.6640 \\
\hline
\end{tabular}
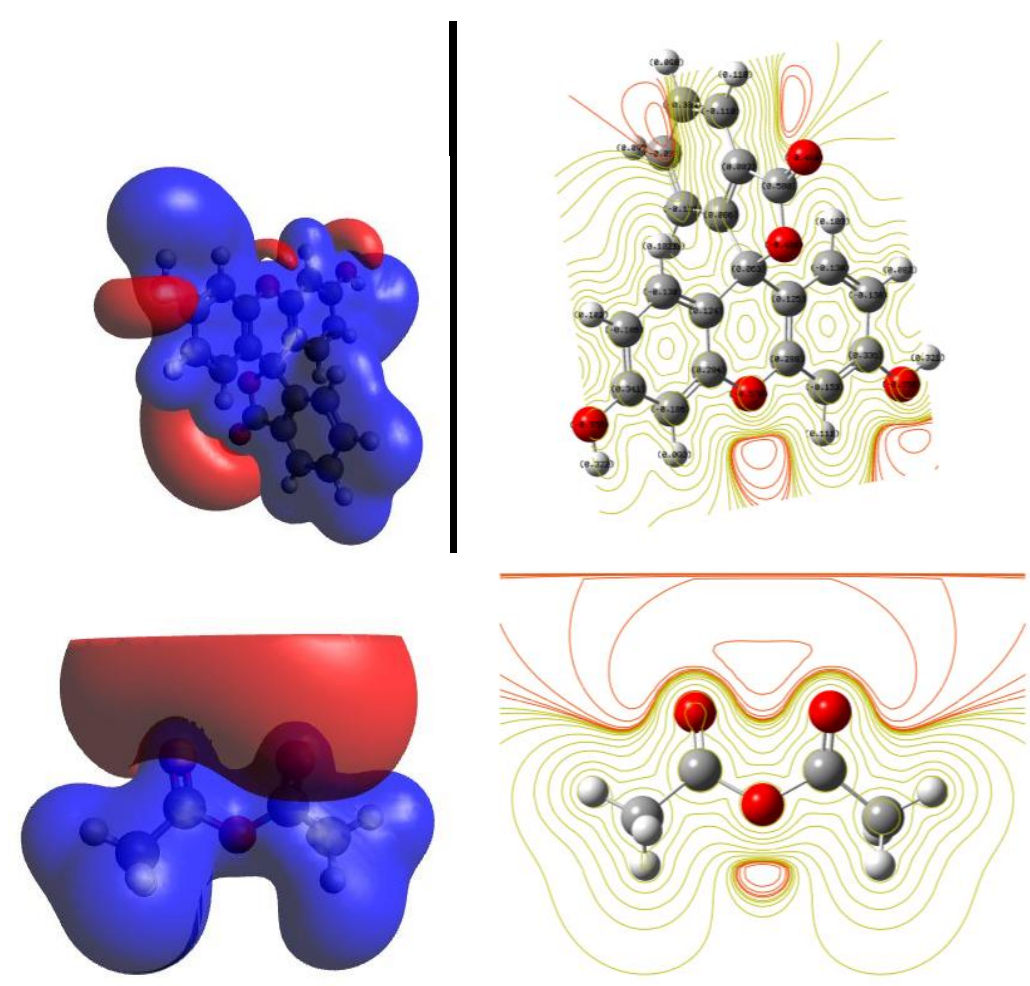

Figure 7. Distribution and localization of the charge density on the atoms of the two reagents in (e) 
- Application of the Gazquez-Mendez rule using condensed local softness ( $\mathrm{Sk}^{+}$and $\mathrm{Sk}^{-}$)

According to the Gazquez-Mendez rule ${ }^{38}$, "Two chemical species interact through atoms with equal or similar softness". The local softness values $\mathbf{S k}^{-}$for the reactive atoms of fluorescein and local softness $\mathbf{S k}^{+}$for the reactive atoms of acetic anhydride calculated with the N.P.A. population analysis are given in Table 10.

Table 10. Fukui indices ( $\mathbf{f} \mathbf{k}^{+}$and $\mathbf{f} \mathbf{k}^{-}$) and $\mathbf{S} \mathbf{k}^{-}$local softness values for reactive fluorescein and $\mathbf{S k}^{+}$local softness atoms for acetic anhydride reactive atoms calculated by N.P.A. populations.

Local indices N.P.A.

\begin{tabular}{|c|c|c|c|c|c|}
\hline \multicolumn{3}{|c|}{ Basic fluorescein } & \multicolumn{3}{|c|}{ Acetic anhydride } \\
\hline Atoms & $\mathbf{f k}^{-}$ & $\mathbf{S k}^{-}$ & Atoms & $\mathbf{f k}^{+}$ & $\mathbf{S k}^{+}$ \\
\hline $\mathbf{C}_{1}$ & -0.008 & -0.037 & $\mathbf{C}_{1}$ & -0.032 & -0.027 \\
\hline $\mathrm{C}_{2}$ & 0.110 & 0.531 & $\mathrm{C}_{2}$ & 0.195 & 0.164 \\
\hline $\mathbf{C}_{3}$ & 0.080 & 0.388 & $\mathbf{O}_{3}$ & 0.012 & 0.010 \\
\hline $\mathrm{C}_{4}$ & -0.003 & -0.013 & $\mathrm{C}_{4}$ & 0.194 & 0.163 \\
\hline $\mathrm{C}_{5}$ & 0.008 & 0.039 & $\mathrm{C}_{5}$ & -0.032 & -0.027 \\
\hline $\mathrm{C}_{6}$ & 0.083 & 0.403 & $\mathbf{O}_{6}$ & 0.153 & 0.045 \\
\hline $\mathrm{C}_{7}$ & -0.008 & 0.037 & $\mathbf{O}_{7}$ & 0.153 & 0.128 \\
\hline $\mathrm{C}_{8}$ & 0.110 & 0.531 & & & \\
\hline O9 & 0.015 & 0.074 & & & \\
\hline $\mathrm{C}_{10}$ & -0.014 & 0.067 & & & \\
\hline $\mathrm{C}_{11}$ & 0.008 & 0.039 & & & \\
\hline $\mathrm{C}_{12}$ & 0.083 & 0.403 & & & \\
\hline $\mathbf{C}_{13}$ & 0.080 & 0.388 & & & \\
\hline $\mathrm{C}_{14}$ & -0.003 & 0.013 & & & \\
\hline $\mathbf{O}_{15}$ & 0.008 & 0.039 & & & \\
\hline $\mathrm{C}_{16}$ & 0.005 & 0.026 & & & \\
\hline $\mathbf{O}_{17}$ & 0.010 & 0.047 & & & \\
\hline $\mathrm{C}_{18}$ & 0.006 & 0.029 & & & \\
\hline $\mathrm{C}_{19}$ & -0.021 & -0.101 & & & \\
\hline $\mathbf{C}_{20}$ & 0.005 & 0.026 & & & \\
\hline $\mathbf{C}_{21}$ & 0.010 & 0.050 & & & \\
\hline $\mathrm{C}_{22}$ & 0.004 & 0.018 & & & \\
\hline $\mathrm{C}_{23}$ & 0.006 & 0.028 & & & \\
\hline $\mathbf{O}_{24}$ & 0.135 & 0.657 & & & \\
\hline $\mathbf{O}_{25}$ & 0.135 & 0.657 & & & \\
\hline
\end{tabular}

With $\mathrm{Sk}^{+}=\mathrm{S}^{*} \mathrm{fk}^{+}\left(\mathrm{S}=\mathbf{1} / 2 * \eta=0.1037 \mathrm{eV}^{-1}\right)$ and $\mathrm{Sk}^{-}=\mathrm{S}^{*} \mathrm{fk}^{-}\left(\mathrm{S}=\mathbf{0} .1671 \mathrm{eV}^{-1}\right)$.

Table 10 also shows that the most favored interactions take place between the atom $\mathbf{C}_{2}$ and $\mathbf{C}_{4}$ of acetic anhydride and the $\mathbf{O}_{24}$ and $\mathbf{O}_{25}$ fluorescein (neighboring local softness) which is in good agreement with the experimental results.

\section{Anticorrosion behavior of the synthetic compound}

\subsection{Stability in an acid environment}

The technique is simple after solubilization of NAR3 in acidic solution; we used liq-liq extraction $\left(\mathrm{H}_{2} \mathrm{O} / \mathrm{CH}_{2} \mathrm{Cl}_{2}\right)$ to recuperate our product after that the infrared analysis used in $\mathrm{Kbr}$.

To find available information about the stability of NAR3 inhibitor in acidic solution, the infrared analysis has been investigated before and after contact with the hydrochloric acid solution. 

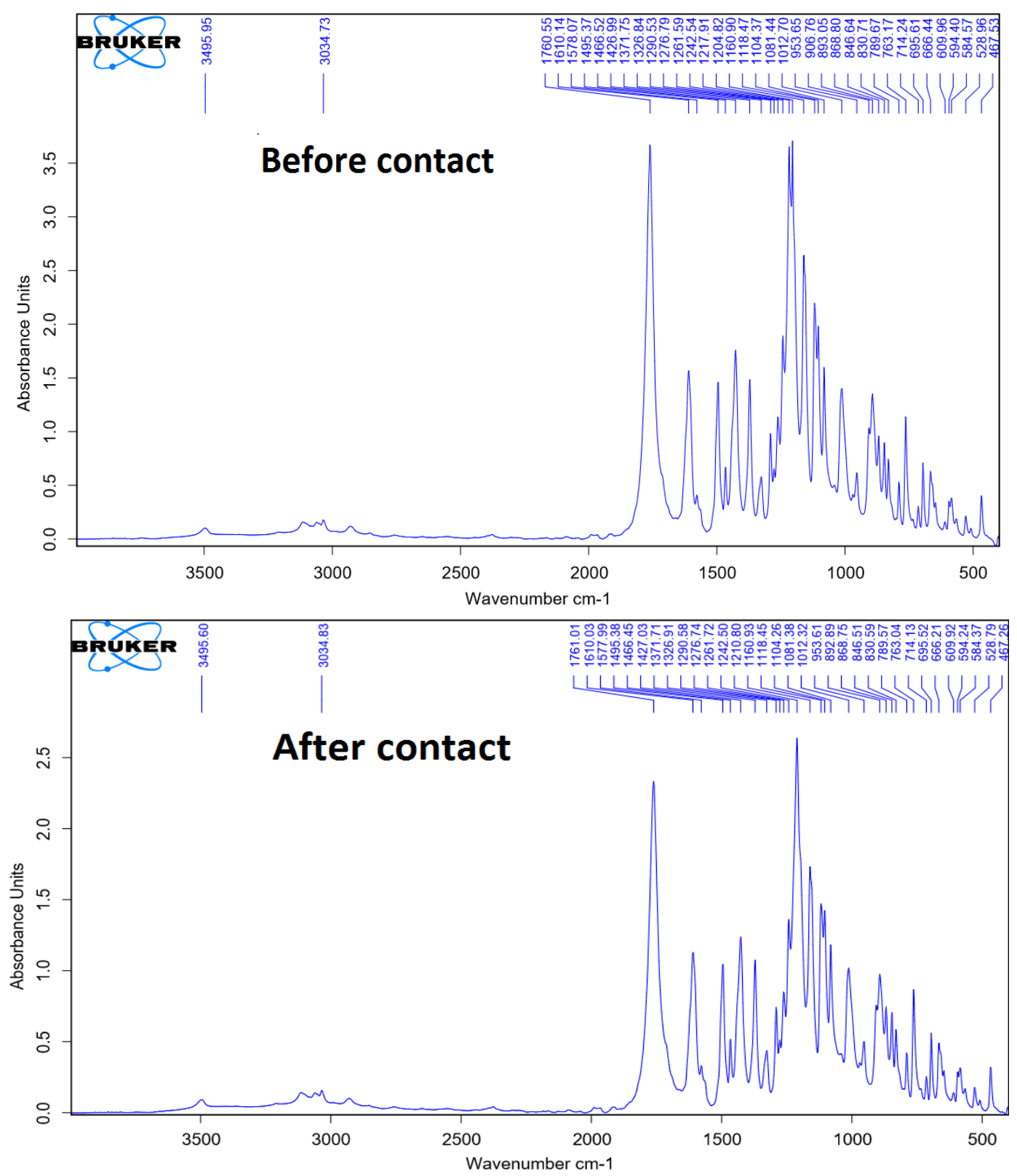

Figure 8. I.R. spectrums of NAR3 inhibitor before and after contact in acid solution

From infrared spectrums Figure 8 and Table 11, the result obtained shows the stability behavior of NAR3 inhibitor in acidic medium. Therefore, any transformation of organic function that reflects the stability of the studied inhibitor. Then, this result can be justified the choice of an acid environment as a corrosion medium.

Table11. Bands assignments $\left(\mathrm{cm}^{-1}\right)$ of NAR3 in the I.R. spectrum.

\begin{tabular}{|c|c|}
\hline Assignment & Frequencies $\left(\mathbf{c m}^{-\mathbf{1}}\right)$ \\
\hline $\boldsymbol{v}(\mathbf{O}-\mathbf{H})$ & $3800-3600$ \\
\hline$v(=\mathbf{C}-\mathbf{H})$ aromatic & $3200-2800$ \\
\hline $\boldsymbol{v}(\mathbf{C}=\mathbf{O})$ & $1700-1550$ \\
\hline$v(\mathbf{C}-\mathbf{O})$ & $1500-1080$ \\
\hline
\end{tabular}

\subsection{Absorbance measurements}

The absorbance difference measurement is a simple technique which applied using a U.V./Visible spectrophotometer (UV-6300PC, Double Beam Spectrophotometer). The mild steel samples are immersed in these solutions and placed in thermostated water during $6 \mathrm{~h}$ at $298 \mathrm{~K}$. Then, the absorbance measurements $\left(\mathrm{A}^{\circ}\right)$ and $(\mathrm{A})$ are taken before and after immersion at a wavelength of 300$310 \mathrm{~nm}$. 
The difference between $\left(\mathrm{A}^{\circ}\right)$ and $(\mathrm{A})$ was recorded as the absorbance difference of the corrodent in each case. All the reported readings are an average of five experimental readings.

The inhibition efficiency of NAR3 inhibitor was calculated using the following equation ${ }^{40,41}$ :

$$
\operatorname{IE}(\%)=\frac{A^{\circ}-A}{A^{\circ}} * 100
$$

Where $\left(\mathrm{A}^{\circ}\right)$ and $(\mathrm{A})$ are absorbance for mild steel without and with $\mathrm{NAR} 3$ in $1 \mathrm{M} \mathrm{HCl}$ medium at 298K.
Table 12 shows the percentage of inhibition effect of mild steel at various concentrations of fluorescein in acidic media at $298 \mathrm{~K}$ from absorbance difference measurements. The result obtained from this technique indicates that the inhibition efficiency increases slightly with inhibitor concentrations to achieve $90 \%$ at $10^{-4} \mathrm{M}$. This inhibition behavior of synthetic compound can be reported to the ability of this compound to form protective film onto the steel surface, through the vacant d-orbital of iron and delocalized $\pi$ electrons on the length of inhibitor molecule ${ }^{41-45}$.

Table12. Inhibition efficiency and Absorbance difference for NAR3 in 1M HCl solution at 298K after 6h of immersion.

\begin{tabular}{|c|c|c|c|}
\hline Medium & Concentration $(\mathbf{m o l} / \mathbf{L})$ & Absorbance difference & \multicolumn{2}{|c|}{ Efficiency } \\
\hline $\mathbf{1 M}$ HCl & -- & 0.558 & - \\
\hline & $10^{-4}$ & 0.056 & $\mathbf{9 0}$ \\
\hline \multirow{2}{*}{ NAR3 } & $10^{-5}$ & 0.067 & $\mathbf{8 8}$ \\
\cline { 2 - 4 } & $10^{-6}$ & 0.134 & $\mathbf{7 6}$ \\
\hline
\end{tabular}

\section{Surface analysis SEM/EDX}

The surface analysis result of mild steel in the presence and absence of NAR3 inhibitor after immersion throughout 6 hours at $298 \mathrm{~K}$ was investigated to point out the percentage of atoms absorbable on the surface of the working electrode ${ }^{46}$

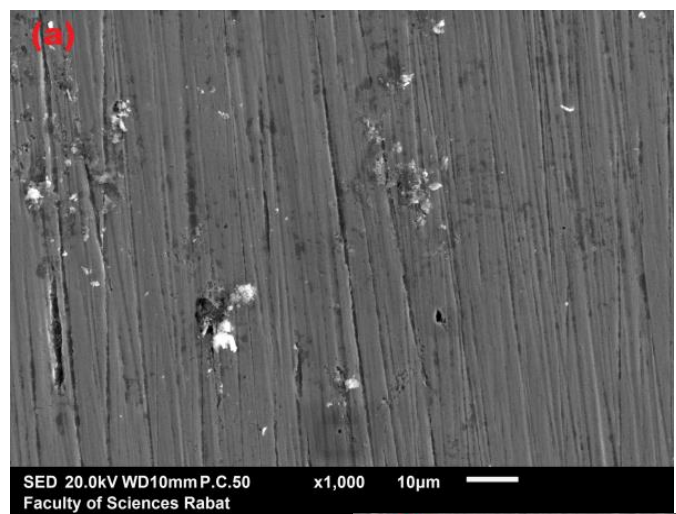

SEM micrographs are presented in Figure 9. The image of mild steel after immersion in $1 \mathrm{M} \mathrm{HCl}$ shows a rough surface compared with the mild steel after immersed in $10^{-4} \mathrm{M}$ of NAR3 inhibitor due to the formation of a heterogeneous protective film ${ }^{42}$ (Figure11(C)).
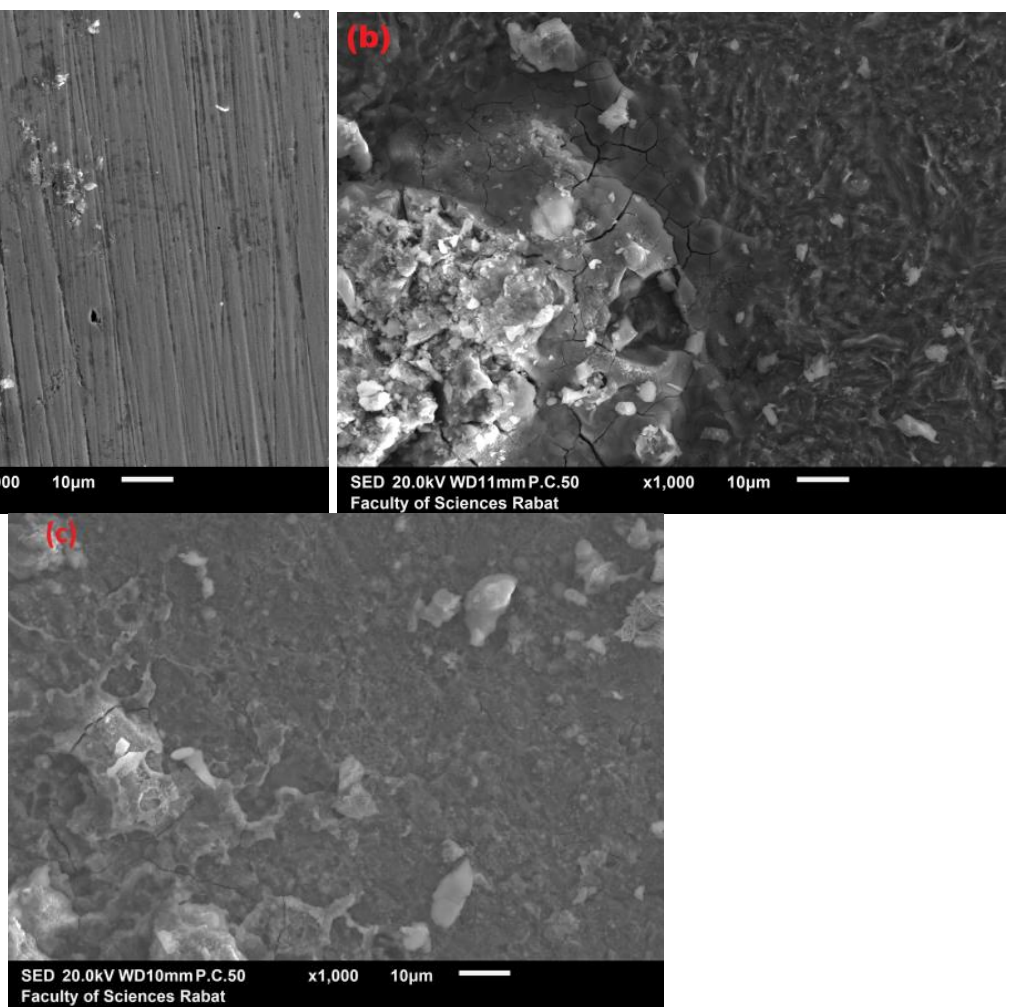

Figure 9. S.E.M. micrographs of mild steel before immersion (a) after $6 \mathrm{~h}$ immersion in $1 \mathrm{M}$ of $\mathrm{HCl}$ (b) after immersion in $10^{-4} \mathrm{M}$ of NAR3 inhibitor (c)

The E.D.X. the technique has been used to identify the chemical composition of the working electrode and the component adsorbed onto the mild steel surface before and after immersed in a different 
solution with and without NAR3 inhibitor at the optimum concentration.

The E.D.X. Spectra showing in Figure 10 and the percentage atomic of various atoms adsorbed on the surface of the working electrode are regrouped in Table 13. It is clear from the difference between the values of percentage atomic for mild steel after immersed in uninhibited and inhibited solution. On the other hand, the percentage of chlorine element was less than that obtained in $1 \mathrm{M} \mathrm{HCl}$ indicating the adsorption behavior of our compounds that reflect the protection behavior of NAR3 inhibitor against corrosion in acidic medium ${ }^{47}$.
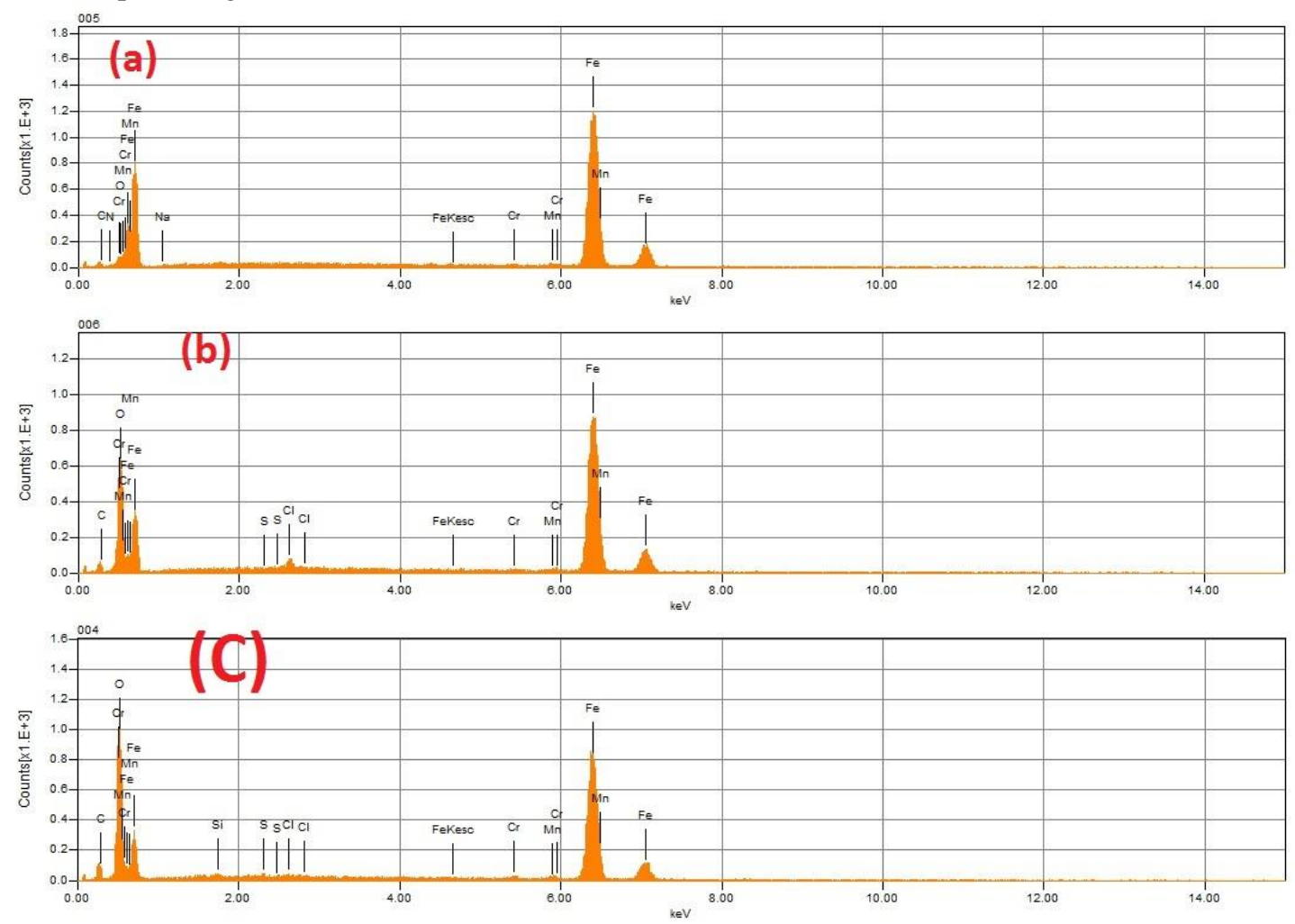

Figure 10. E.D.X. spectra of mild steel before immersion (a) after $6 \mathrm{~h}$ immersion in $1 \mathrm{M}$ of $\mathrm{HCl}$ (b) after immersion in $10^{-4} \mathrm{M}$ of NAR3 inhibitor $(\mathrm{C})$

Table13. Percentage atomic contents of elements obtained from E.D.X. spectra.

\begin{tabular}{|l|c|c|c|c|c|c|}
\hline \multicolumn{1}{|c|}{ Elements adsorbed } & Fe & C & Cr & Mn & Cl & O \\
\hline Mild steel & 96.01 & 2.14 & 0.65 & 0.97 & - & 0.23 \\
\hline Mild steel in 1M of HCl & 83.91 & 4.25 & 0.37 & 0.50 & 2.97 & 8.00 \\
\hline Mild steel in 10-4 Mof NAR3 & 64.06 & 7.48 & 0.78 & 0.95 & 0.22 & 26.51 \\
\hline
\end{tabular}

\section{Conclusion}

The nucleophilic substitution of fluorescein with acetic anhydride occurred under very mild conditions and led to the 3-oxo-3H-spiro[isobenzofuran-1,9'xanthene]-3',6'-diyl diacetate in high yield. Our way of synthesizing this product is economical, environmentally friendly than the catalytic process and also achieve better efficiency.

The structure of the synthesized product was analyzed by M.S., Infrared, ${ }^{13} \mathrm{C}$ N.M.R. and ${ }^{1} \mathrm{H}$ N.M.R. This reaction has been studied using MARVINSKETCH to find a range of $\mathrm{pH}$ in the major form of fluorescein in basic medium and Gaussian 09 program within the DFT calculations at the B3LYP/6-31(d, p) computational level. The exothermic character of this reaction makes the formation of the new product $\mathbf{3}$ irreversible thermodynamically and kinetically favored in good agreement with the experimental result.

In addition, the anti-corrosion behavior of the synthetic product has been evaluated using the difference absorbance method; the result reflects the higher inhibition effect of NAR3 against corrosion of mild steel in $1 \mathrm{M} \mathrm{HCl}$.

\section{Acknowledgments}

We thank the CNRST for the financial support of this work (PROTARS D13/03, Morocco).

\section{References}

1- A. Kumari, R. K. Singh, Medicinal chemistry of indole derivatives: Current to future therapeutic prospectives, Bioorg. Chem, 2019, 89, 103021. 
2- R. Kharb, P. C. Sharma, M. S. Yar, Pharmacological significance of triazole scaffold, J. Enzyme Inhib. Med. Chem, 2011, 26, 1-21.

3- A. Kashyap, O. Silakari, Triazoles: Multidimensional 5-membered nucleus for designing multitargeting agents. In Key Heterocycle Cores for Designing Multitargeting Molecules; Elsevier: Amsterdam. Netherlands, 2018, 323-342.

4- C. V. Maftei, E. Fodor, P. G. Jones, C. G. Daniliuc, M. H. Franz, G. Kelter, H. Fiebig, M. Tamm, I. Neda, Novel 1.2.4-oxadiazoles and trifluoromethylpyridines related to natural products: Synthesis. structural analysis and investigation of their antitumor activity, Tetrahedron, 2016, 72, 1185-1199.

5- I. Neda, T. Kaukorat, R. Schmutzler, U. Niemeyer, B. Kutscher, J. Pohl, J.Engel, Benzodiaza-, Benzoxaza- and benzodioxaphosphorinones-formation, reactivity, structure and biological activity, Phosphorus Sulfur Silicon 2000, 162, 81-218.

6- M. Simon, C. sunderlik, L. Cotarca, M. T. Caproiu, I. Neda, M. C. Turoczi, R. Volpicelli, Synthesis of new active 0-nitrophenyl carbamates, Synth. Comun., 2005, 35, 1471-1479.

7- Y. Mohammad, K. M. Fazili, K. A. Bhat, T. Ara, Synthesis and biological evaluation of novel 3-O-tethered triazoles of diosgenin as potent antiproliferative agents, Steroids, 2017, 118, 1-8.

8- M. Huang, Z. Deng, J. Tian, T. Liu, Synthesis and biological evaluation of salinomycin triazole analogues as anticancer agents, Eur. J. Med. Chem., 2017, 127, 900-908.

9- R. Gujjar, A. Marwaha, F. El Mazouni, J. White, K. L. White, S. Creason, D. M. Shackleford, J. Baldwin, W. N. Charman, F. S. Buckner, Identification of a metabolically stable triazolopyrimidine-based dihydroorotate dehydrogenase inhibitor with antimalarial activity in mice, J. Med. Chem., 2009, 52, 1864-1872.

10-M. Chen, S. Lu. G. Yuan, S. Yang, X. Du, Synthesis and antibacterial activity of some heterocyclic $\beta$-enamino ester derivatives with 1 . 2. 3-triazole, Heterocycl. Commun., 2000, 6, 421-426.

11-A. Ayati, S. Emami, A. Foroumadi, The importance of triazole scaffold in the development of anticonvulsant agents, Eur. J. Med. Chem., 2016, 109, 380-392.

12-T. Akhtar, S. Hameed, K. M. Khan, M. I. Choudhary, Syntheses, urease inhibition, and antimicrobial studies of some chiral 3-substituted-4-amino-5-thioxo-1H, 4H-1.2.4-triazoles, Med. Chem., 2008, 4, 539-543.

13-L. Sevaille, L. Gavara, C. Bebrone, F. De Luca, L. Nauton, M. Achard, P. Mercuri, S. Tanfoni, L. Borgianni, C. Guyon, 1.2.4-Triazole-3-thione compounds as inhibitors of dizinc metallo- $\beta$ lactamases, Chem Med Chem., 2017, 12, 972-985.

14-P. Raffaello, Mono- and Di-Quaternized 4,4'Bipyridine Derivatives as Key Building Blocks for Medium- and Environment-Responsive Compounds and Materials, Molecules, 2020, 25, $1-30$.

15-S. Achamlale, E. H. Mabrouk, A. Elachqar, A. El Hallaoui, S. El Hajji, A. Alami, J. Bellan, M. R. Mazières, J. G. Wolf, M. Pierrot, Synthesis and Thermal Isomerization of Carboxylic and Phosphonic $\alpha$-Aminoesters Substituted with a Triazole Ring, Phosphorus, Sulfur, and Silicon and the Related Elements, 2007, 182, 357-367.

16-E. H. Mabrouk, A. Elachqar, A. Alami, A. El Hallaoui, S. El Hajji, One-pot regioselective synthesis of n-benzoyl 2-amino-3,4-dihydro-3oxo-2h-1,4-benzothiazines, Oriental Journal of Chemistry, 2010, 26(4), 1249-1255.

17-E. H. Mabrouk, A. Elachqar, A. El Hallaoui, A. Alami, S. El Hajji, J. Martinez, V. Rolland, Synthesis of new racemic $\alpha$-heterocyclic $\alpha, \alpha$ diaminoesters and $\alpha$-aminoester carboxylic, Arabian Journal of Chemistry, 2013, 6, 93-96.

18-L. Lingjun, L. Jiyuan, D. Wenhao, G. Feng, C. Kaixian, Z. Yu, L. Hong, Rhodium(III)Catalyzed Redox-Neutral [3+3] Annulation of N-nitrosoanilines with Cyclopropenones: A Traceless Approach to Quinolin-4(1H)-One Scaffolds, Molecules, 2020, 25, 268-282.

19-L. Mousa, R. M. Al-Smadi, M. Amjad, F. K. Omar, M. M. Majed, H. A. Karem, Synthesis, Characterization, Antimicrobial Activity, and Genotoxicity Assessment of Two Heterocyclic Compounds Containing 1.2.3-Selena- or 1.2.3Thiadiazole Rings, Molecules, 2019, 24, 4082-4092.

20-S. N. Sirakanyan, E. K. Akopyan, R. G. Paronikyan, A. G. Akopyan, A. A. Ovakimyan, Synthesis and anticonvulsant activity of 7(8)amino derivatives of condensed thieno[3.2-d] pyrimidines, Pharm. Chem. J., 2016, 50, 296-300.

21-S. N. Sirakanyan, A. Geronikaki, D. Spinelli, E. K. Hakobyan, V. G. Kartsev, A. Petrou, A. A. Hovakimyan, Synthesis and antimicrobial activity of new amino derivatives of pyrano[4".3":40 .50]pyrido[30.20:4.5] thieno[3.2-d]pyrimidine, An. Acad. Bras. Cienc., 2018, 90, 1043-1057.

22-S. N. Sirakanyan, D. Spinelli, A. Geronikaki, V. G. Kartsev, E. K. Hakobyan, A. A Hovakimyan,. Synthesis and antimicrobial activity of new derivatives of pyrano[4".3":40.50]pyrido[30.20:4.5] thieno[3.2d]pyrimidine and new heterocyclic systems, Synth. Commun., 2019, 49, 1262-1276.

23-N. S. Samvel, S. Domenico, G. Athina, K. H. Elmira, S. Harutyun, A. Erik, Z. Hovakim, E. N. Lusine, S. A. Anahit, S. D. Irina, E. M. Rafayel, 
A. H. Anush, Synthesis, Antitumor Activity, and Docking Analysis of New Pyrido-

[30,20:4,5]furo(thieno)[3,2-d]pyrimidin-8amines, Molecules, 2019, 24, 3952-3965.

24-S. Cascioferro, B. Parrino, V. Spanò, A. Carbone, A. Montalbano, P. Barraja, P. Diana, G. Cirrincione, An overview on the recent developments of 1,2,4-triazine derivatives as anticancer compounds, Eur. J. Med. Chem., 2017, 142, 328-375.

25-M. Sztanke, K. Sztanke, B. Rajtar, Ł. Swiatek, A. Boguszewska, M. Polz-Dacewicz, the influence of some promising fused azaisocytosine-containing congeners on zebrafish (Danio rerio) embryos/larvae and their antihaemolytic, antitumour and antiviral activities, Eur. J. Pharm. Sci., 2019, 132, 34-43.

26-P. M. S Monk, The Viologens: Physicochemical Properties, Synthesis and Applications of the Salts of 4,4-Bipyridine; Chichester; New York: Wiley, 1998.

27-M. Baroncini, S. Silvi, A. Credi, Photo- and Redox-Driven Artificial Molecular Motors, Chem. Rev., 2020, 120, 1, 200-268.

28-Y. Wang, M. Frasconi, J. F. Stoddart, Introducing Stable Radicals into Molecular Machines, A.C.S. Cent. Sci., 2017, 3, 927-935.

29-S. Erbas-Cakmak, D. A. Leigh, C. T. McTernan, A. L. Nussbaumer, Artificial Molecular Machines, Chem. Rev., 2015, 115, 10081-10206.

30- A. C. Fahrenbach, Z. Zhu. D. Cao, W. G. Liu, H. Li, S. K. Dey, S. Basu, A. Trabolsi, Y. Y. Botros, Goddard III. W. A, J. F. Stoddart, Radically Enhanced Molecular Switches, J. Am. Chem. Soc., 2012, 134, 16275-16288.

31-B. L. Feringa, W. R. Browne, Molecular Switches; Wiley V.C.H.: Weinheim, Germany, 2011, 2, pp. 792, ISBN 978-3-527-63441-5.

32-V. Buchmann, K. D. Weston, M. Sauer, Spectroscopic study and evaluation of redabsorbing fluorescent dyes, Bioconjugate Chem., 2003, 14, 195-204.

33-G. Cosa, K. S. Focsaneanu, J. R. N. Mclean, J. P. McNamee, J. C. Scaiano, Photophysical properties of fluorescent DNA-dyes bound to single- and double-stranded D.N.A. in aqueous buffered solution, Photochem. Photobiol., 2001, 73, 585-599.

34-E. V. R. de Castro, F. E. Jorge, Accurate universal Gaussian basis set for all atoms of the periodic table, Journal of Chemical Physics, 199, 108, 5225-5229.

35-N. Chafai, S. Chafaa, K. Benbouguerra, D. Daoud, A. Hellal, M. Mehri, Synthesis, characterization and the inhibition activity of a new $\alpha$-aminophosphonic derivative on the corrosion of XC48 carbon steel in $0.5 \mathrm{M} \mathrm{H} 2 \mathrm{SO} 4$ : Experimental and theoretical studies, Journal of the Taiwan Institute of Chemical Engineers, 2017, 70, 331-344.
36-A. Hellal, S. Chafaa, N. Chafai, L. Touafri, Synthesis, antibacterial screening and DFT studies of series of $\alpha$-amino-phosphonates derivatives from aminophenols, Journal of Molecular Structure, 2017, 1134, 217-225.

37-L. R. Domingo, P. Pérez, The nucleophilicity N index in organic chemistry, Organic and Biomolecular Chemistry, 2011, 9, 7168-7175.

38-P. Pérez, L. R. Domingo, M. Duque-Noreňa, E. A. Chamorro, Condensed-to-atom nucleophilicity index. An application to the director effects on the electrophilic aromatic substitutions, Journal of Molecular Structure (Theochem), 2009, 895, 86-91.

39-H. Eshghi, N. Mirzaie, A. Asoodeh, Dyes and Pigments Synthesis of fluorescein aromatic esters in the presence of $\mathrm{P}_{2} \mathrm{O}_{5} / \mathrm{SiO}_{2}$ as catalyst and their hydrolysis studies in the presence of lipase, Dye Pigment, 2011, 89, 120-126.

40- A. I. Onen, B. T. Nwufo, E. Ebenso, R. M. Hlophe, Titanium (IV) Oxide as Corrosion Inhibitor for Aluminium and Mild Steel in Acidic Medium, International Journal of Electrochemical Science, 2010, 5, 1563 - 1573.

41-A. Ezeibe, E. Nleonu, A. Ahumonye, Thermodynamics Study of Inhibitory Action of Lignin Extract from Gmelina arborea on the corrosion of mild steel in dilute Hydrochloric Acid, International Journal of Scientific Engineering and Research, 2019, 7(2), 133-136.

42-F. El-Hajjaji, M. Messali, M. V. Martínez de Yuso, E. Rodríguez-Castellón, S. Almutairi, Teresa J. Bandosz, M. Algarra, Journal of Colloid and Interface Science, 2019, 541, 418-424.

43-F. El-Hajjaji, M. Messali, A. Aljuhani, M. R. Aouad, B. Hammouti, M. E. Belghiti, D. S. Chauhan, M. A. Quraishi, Journal of Molecular Liquids, 2019, 249, 997-1008.

44-R. Salim, E. Ech-chihbi, H. Oudda, F. El Hajjaji, M. Taleb, S. Jodeh. A review on the assessment of Imidazo[1,2-a] pyridines As corrosion inhibitor of metals, J Bio Tribo Corros, 2019, 5,14 .

45-F. El Hajjaji, F. Abrigach, O. Hamed, A. R. Hasan, M. Taleb, S. Jodeh, E. RodríguezCastellón, M. V. M. Yuso, M. Algarra, Corrosion resistance of mild steel coated with organic material containing pyrazole moiety, Coatings, 2018, 8, 330.

46-N. Arshad, A. K. Singh, M. Akram, F. Perveen, I. Rasheed, F. Altaf, P. A. Channar, A. Saeed, Experimental, theoretical, and surface study for corrosion inhibition of mild steel in $1 \mathrm{M} \mathrm{HCl}$ by using synthetic anti-biotic derivatives, IONICS, 2019, 25, 5057-5075.

47-N. Arshad, F. Altaf, M. Akram, M. Ullah, Furan and Phenyl Substituted Triazolothiadiazine Derivatives as Copper Corrosion Inhibitors: Electrochemical and DFT Studies, Prot Met Phys Chem Surfaces, 2019, 55, 770-780. 